\title{
The comprehensive immunomodulation of NeurimmiRs in haemocytes of oyster Crassostrea gigas after acetylcholine and norepinephrine stimulation
}

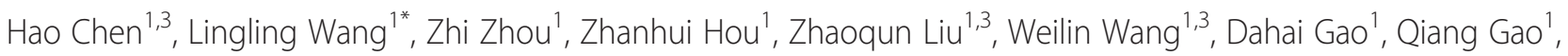
Mengqiang Wang ${ }^{1}$ and Linsheng Song ${ }^{1,2^{*}}$

\begin{abstract}
Background: Neural-endocrine-immune (NEI) system is a major modulation network among the nervous, endocrine and immune system and weights greatly in maintaining homeostasis of organisms during stress and infection. Some microRNAs are found interacting with NEl system (designated NeurimmiRs), addressing swift modulations on immune system. The oyster Crassostrea gigas, as an intertidal bivalve, has evolved a primary NEI system. However, the knowledge about NeurimmiRs in oysters remains largely unknown.
\end{abstract}

Results: Six small RNA libraries from haemocytes of oysters stimulated with acetylcholine (ACh) and norepinephrine (NE) were sequenced to identify neurotransmitter-responsive miRNAs and survey their immunomodulation roles. A total of 331 miRNAs (132 identified in the present study plus 199 identified previously) were subjected to expression analysis, and twenty-one and sixteen of them were found ACh- or NE-responsive, respectively (FDR $<0.05)$. Meanwhile, 21 miRNAs exhibited different expression pattern after ACh or NE stimulation. Consequently, 355 genes were predicted as putative targets of these neurotransmitter-responsive miRNAs in oyster. Through gene onthology analysis, multiple genes involved in death, immune system process and response to stimulus were annotated to be modulated by NeurimmiRs. Besides, a significant decrease in haemocyte phagocytosis and late-apoptosis or necrosis rate was observed after ACh and NE stimulation $(p<0.05)$ while early-apoptosis rate remained unchanged.

Conclusions: A comprehensive immune-related network involving PRRs, intracellular receptors, signaling transducers and immune effectors was proposed to be modulated by ACh- and NE-responsive NeurimmiRs, which would be indispensable for oyster haemocytes to respond against stress and infection. Characterization of the NeurimmiRs would be an essential step to understand the NEl system of invertebrate and the adaptation mechanism of oyster.

Keywords: Oyster, NeurimmiR, Acetylcholine, Norepinephrine, Immunomodulation, Neural-endocrine-immune system

\section{Background}

Neural-endocrine-immune (NEI) system, defined firstly by Besedovsky and Sorkin in 1977, is a closely interacted network among the nervous, endocrine and immune system [1]. These three systems communicate actively with each other by releasing neurotransmitters, hormones and cytokines, respectively [2]. The well balanced

\footnotetext{
*Correspondence: wanglingling@qdio.ac.cn; Ishsong@ms.qdio.ac.cn 'Key Laboratory of Experimental Marine Biology, Institute of Oceanology, Chinese Academy of Sciences, Qingdao, China

Full list of author information is available at the end of the article
}

NEI system and reciprocal regulation inside are essential for organisms to maintain homeostasis during the stress or infection [2]. Acetylcholine (ACh) and norepinephrine (NE) have been considered as representative neurotransmitters in parasympathetic and sympathetic nervous system, respectively $[3,4]$, and they contribute an intensive modulation on the immune response of mammals during stress and bacteria challenge $[5,6]$.

Recently, microRNAs (miRNAs) have been identified as an important mechanism to modulate the NEI system in mammals. As a class of endogenously encoded single- 
strand non-coding RNAs, miRNAs have been suggested as vital regulators in gene expression by binding to their 3'-UTR [7]. To date, a great number of miRNAs have been identified from diverse species, with striking conservation in their secondary structure and length ( 22 nt) [8]. It has been estimated that miRNAs could be involved in the modulation of almost all biological processes, including growth, development, cell differentiation and immunity $[7,9]$.

Accumulating evidences has recently demonstrated that some miRNAs (designated NeurimmiRs) could act as "negotiators" within the NEI system and function indispensably in maintaining the immune homeostasis during infection [10-12]. For example, miR-132, a wellknown NeurimmiR in mammals, could repress the expression of acetylcholinesterase after LPS stimulation, resulting in the attenuation of the vagus nerve and the release of tumor necrosis factor and interleukin-6 [11]. Other eight miRNAs were also identified as NeurimmiRs, which shared close connection with various neuropathologies [10]. However, less is known about NeurimmiRs in invertebrates who might own more preliminary NEI system than vertebrates.

The Mollusca is a large diverse phylum in invertebrates and possess the ancient neuroendocrine system, such as ancient cholinergic and catecholaminergic system, similar to that in mammals $[13,14]$. The ancient molluscan neuroendocrine system, can be activated by bacteria stimulation and modulate the immune response in turn [15]. As an intertidal bivalve, oysters Crassostrea gigas are continuously suffered by environmental stress, which attracts more attention to the balance of NEI system. The available genome information [16] and the knowledge of immune mechanism [17] as well as some previously identified miRNAs [18] make it suitable to investigate the modulation of NEI system in oyster [19]. The purposes of the present study were to (1) further identify neurotransmitter-induced NeurimmiRs from oyster, (2) characterize miRNA expression patterns after the neurotransmitter stimulation, (3) survey the potential modulation of NeurimmiRs on the immune response of oyster, hopefully providing new hints for the dynamic regulation within the NEI system in mollusc.

\section{Result}

\section{Overview of small RNA sequencing}

Six small RNA libraries constructed from corresponding samples in PBS control group, ACh stimulation group and NE stimulation group were sequenced by Ion Torrent Proton. Totally, 50.0 M, 57.4 M, 54.7 M, 60.6 M, 67.9 M and $63.6 \mathrm{M}$ raw reads were obtained from those six libraries, respectively (Additional file 1: Table S1). After discarding the disqualified reads and incorporating identical reads, $1.9 \mathrm{M}, 2.0 \mathrm{M}, 1.6 \mathrm{M}, 2.1 \mathrm{M}, 2.3 \mathrm{M}$ and $2.5 \mathrm{M}$ unique reads were obtained correspondingly (Additional file 1: Table S1). Two peaks were observed in the length distribution (Additional file 2: Figure S1) of all the unique reads $(8.6 \mathrm{M})$ obtained from these six libraries. A total of 715,372 reads remained with copy number more than 6 , and were applied for the subsequent alignment with Rfam database and oyster mRNA. Finally, 519,571 reads were retained for further mapping to the genome (Additional file 3: Table S2).

\section{The miRNAs identified from oyster haemocytes}

To identify miRNAs expressed in oyster haemocytes after neurotransmitter stimulation, a total of 6,820 reads which have at least one alignment in genome, were subjected to miRDeep2 software for prediction of the precursor sequence and secondary structure. A total of 132 new miRNAs including 5 known ones and 127 novel ones were identified (Additional file 4: Table S3), among which, 27 miRNAs possessed at least two precursor-coding regions (Fig. 1, Additional file 5: Table S4). Considering $199 \mathrm{miR}-$ NAs (Additional file 4: Table S3) identified previously, a total of 331 miRNAs were discovered in oyster haemocytes. Within those miRNAs, 76 miRNAs shared the same seed sequence with miRNAs identified in other species (designated known miRNAs) and 255 ones possessed new seed sequence (designated novel miRNAs).

\section{Differentially expressed miRNAs after neurotransmitter stimulation}

Copy numbers of the 331 miRNAs identified in oyster haemocytes were counted and further converted to fragments per kilo base of transcript per million fragments mapped (FPKM) value to analyze their expression level (Additional file 6: Table S5). FPKM distributions of total miRNAs in those three groups were analyzed and depicted in box plot (Fig. 2). The bottom and top of the box represented the first and third quartiles of $\log _{10}(\mathrm{FPKM}+1)$ values in corresponding group while the line insides the box stood for the median value. Though the median and third quartile in PBS, ACh and NE groups were similar, the first quartile of control group was significantly lower than that in neurotransmitter stimulation groups (Fig. 2).

Differentially expressed miRNAs after neurotransmitter stimulation were determined subsequently by edgeR software with FDR less than 0.05 (Additional file 7: Table S6). As a result, a sum of 21 miRNAs were found expressed differentially in the ACh stimulation group compared to that in the PBS control group, including 18 increased and three decreased ones (Fig. 3). Ten miRNAs were upregulated after NE stimulation while six were downregulated, compared with that in PBS group (Fig. 3). Five miRNAs (cgi-miR-125, cgi-miR-8, scaffold1144_2255, scaffold1711_599 and scaffold226_18954) were found 


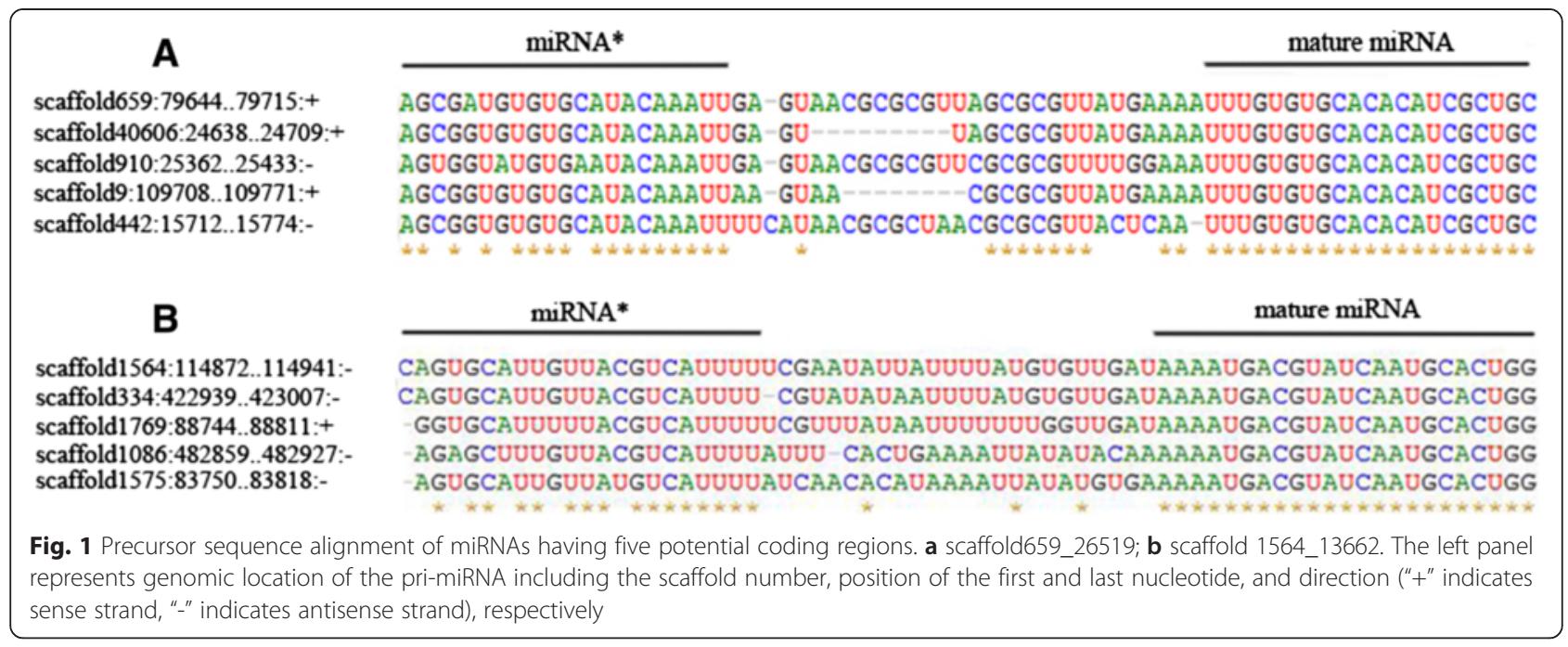

responsive to both the ACh and NE stimulation. Furthermore, 21 miRNAs showed different expression pattern in ACh and NE stimulation groups, among which, eight miRNAs exhibited higher expression level in NE stimulation group and 13 miRNAs exhibited higher expression level in ACh stimulation group (Fig. 3).

Those 38 neurotransmitter-responsive miRNAs were then clustered by Cluster3.0 using FPKM value (Fig. 4). Among them, four miRNAs (cgi-miR-184d, cgi-miR-1989, scaffold785_16815 and scaffold625_3183) decreased merely in ACh group and seven miRNAs (scaffold41304_9, scaffold264_13663, scaffold105_17058, scaffold663_9199, scaffold730_4499, scaffold942_7011 and scaffold987_25421) increased strictly after ACh stimulation. Meanwhile, nine miRNAs responded exclusively to NE stimulation including five (cgi-miR-190, cgi-miR-133,
ci-miR-278, C24628_29044 and scaffold659_26519) upregulated and four (cgi-miR-182, cgi-miR-92d, scaffold1600_212, and scaffold508_4253) down-regulated.

\section{Gene onthology (GO) terms of target genes of neurotransmitter-responsive miRNAs}

A total of 355 oyster genes were predicted as putative targets of those neurotransmitter-responsive miRNAs by miRanda software (Additional file 8: Table S7). The GO term distributions of all target genes were analyzed by Blast2GO software and displayed through Web Gene Ontology Annotation Plot (WEGO) (Fig. 5). Finally, immune-related biological process (death, immune system process and response to stimulus) and molecular function (antioxidant) were annotated from those targets of neurotransmitter-responsive miRNAs.

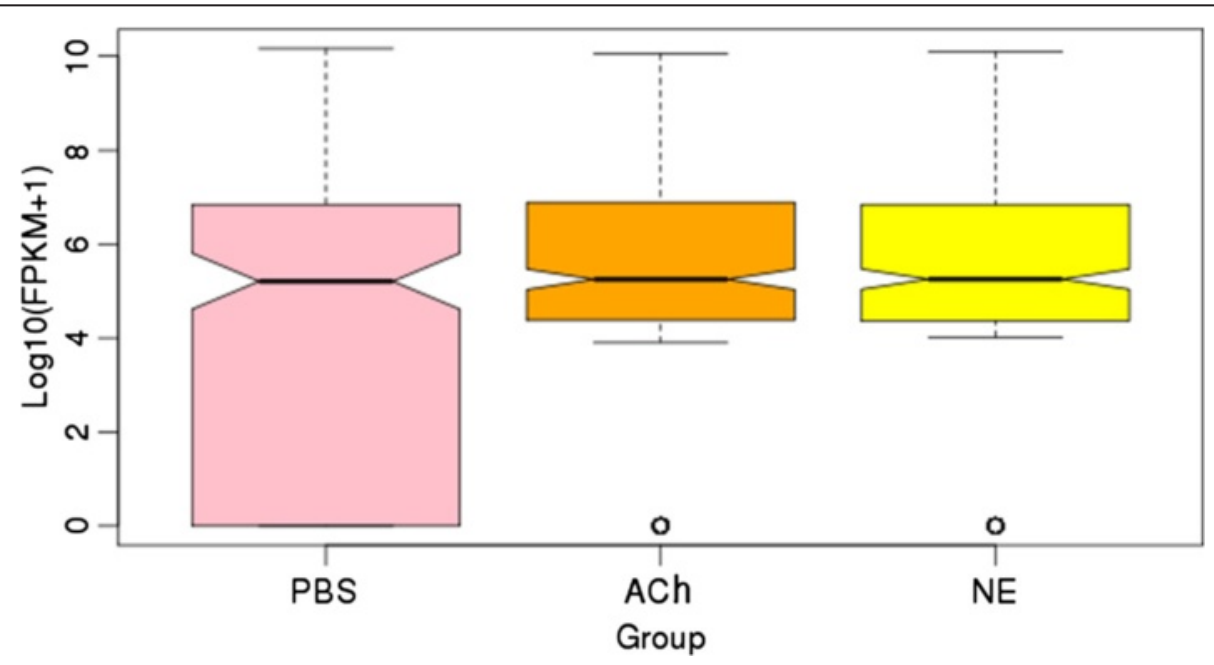

Fig. 2 Expression level of all miRNAs in three groups. Pink: control group; Orange: ACh stimulation group; Yellow: NE stimulation group. The bottom and top of the box represents the first and third quartiles of $\log _{10}(F P K M+1)$ values in corresponding group while the line insides the box stands for the median value. The overall expression level of oyster miRNAs in ACh and NE stimulation groups were significantly higher than that in PBS control group 


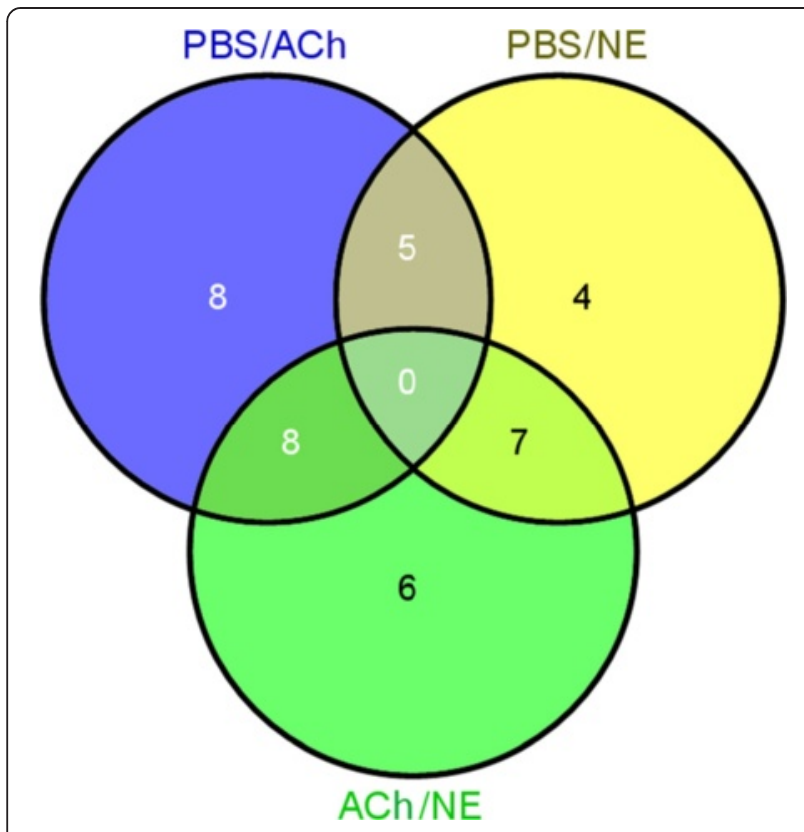

Fig. 3 Grouping of differentially expressed miRNAs. Blue circle represents miRNAs expressed differentially in ACh group when compared with PBS group. Yellow circle indicates differentially expressed miRNAs in PBS/NE comparison while green indicates that in ACh/NE comparison

\section{Immune-related genes targeted putatively by} NeurimmiRs

Diverse immune-related genes involved in pathogen recognition, signaling transduction, immune and stress responses were predicted as putative targets for those neurotransmitter-responsive miRNAs (Table 1). For example, the transcripts of pathogen recognition receptor (PRRs), such as mannose receptor 1 (MRC1, CGI_10013598), C-type mannose receptor 2 (MRC2, CGI_10003643), Toll like receptor 1 (TLR1, CGI_10021136), carcinoembryonic antigen-related cell adhesion molecule 5 (CEACAM5, CGI_10010080), and intracellular receptors, such as multiple epidermal growth factor-like domains 10 (MEGF10, CGI_10022484), muscarinic acetylcholine receptor (mAChR, CGI_10026715), nicotinic acetylcholine receptor (nAChR CGI_10012300), CD63 antigen (CD63, CGI_10024556), were prognosticated to be modulated by some NeurimmiRs (Fig. 6). Some signal transducers annotated as CREB-binding protein (CREBBP, CGI_10004570), Ras-related protein Rab-21 (RAB-21, CGI_10012407), Ras-related protein Rab-5C (RAB-5C, CGI_10016941), E3 ubiquitin-protein ligase mib2 (MIB2, CGI_10012437), TNF alpha-induced protein 3 (TNFAIP3, CGI_10016154), and TNF receptor-associated factor 3 (TRAF3, CGI_10019401) were also suggested to be the targets of NeurimmiRs by miRanda (Fig. 7). Immune and stress effectors such as HSP70 (CGI_10006158, CGI_10014234, CGI_10014235 and CGI_10027276), cytochrome P450
(CGI_10012275, CGI_10011491) and interferon-induced protein 44 (IFI44, CGI_10011953) were also suggested to be manipulated by certain NeurimmiRs (Fig. 8).

\section{Changes of phagocytosis and apoptosis rate of oyster haemocytes after neurotransmitter stimulation}

The phagocytosis and apoptosis rate of oyster haemocytes after neurotransmitter stimulation were evaluated to survey the immunomodulation role of $\mathrm{ACh}$ and $\mathrm{NE}$. Both the phagocytosis rate in the haemocytes of $\mathrm{ACh}$ and NE group dropped significantly when compared with that in control group $(P<0.05)$ (Fig. 9a). No remarkable changes of early-apoptosis rate was found in the ACh and NE groups compared with control group (Fig. 9b) while the late-apoptosis and necrosis rate decreased significantly $(P<0.05)$ (Fig. 9c).

\section{Discussion}

As a class of gene regulator at post-transcription level, miRNAs are usually transcribed by RNA polymerase II and incorporated into RNA-induced silencing complex where they can binds to the 3'-UTR of target genes and induce their translational repression or degradation [20]. Though diverse miRNAs have been identified in regulating immune genes, fewer reports investigated their interactions with neurotransmitter [10]. In the present study, six miRNA libraries from oyster haemocytes after ACh and NE stimulation were sequenced to identify neurotransmitter-responsive miRNAs and further investigate their potential involvements in the modulation of immune response. A total of 132 new miRNAs were identified herein, including 5 known ones and 127 novel ones. In addition with 199 miRNAs identified previously, a total number of 331 miRNAs have been discovered in oyster C. gigas so far. Among those, 255 miRNAs failed to be mapped to any mature miRNAs in the miRBase database, suggesting that they might be oyster-specific. The total number of miRNAs in C. gigas, was larger than that in other molluscs such as Haliotis rufescens [21], Lotti agigantea [21] and Pinctada martensii [22], indicating that they might play indispensable roles in the thrive of oysters in intertidal environment.

ACh and NE have been proved to be vital neurotransmitters in the response against stress and infection $[2,3,23,24]$ and the expression of diverse immunerelated genes could be fast switched by them (3-12 h) $[13,14]$, indicating the participation of miRNAs during the modulation. Accordingly, in the present study, 38 of 331 oyster miRNAs depicted intensively expressional alteration at $6 \mathrm{~h}$ after ACh and NE stimulation. Among them, two ACh-responsive miRNAs (cgi-miR-125 and cgi-miR-8) and six NE-responsive miRNAs (cgi-miR125, cgi-miR-133, cgi-miR-190, cgi-miR-278, cgi-miR-8 and cgi-miR-92d) were also found as immune- 


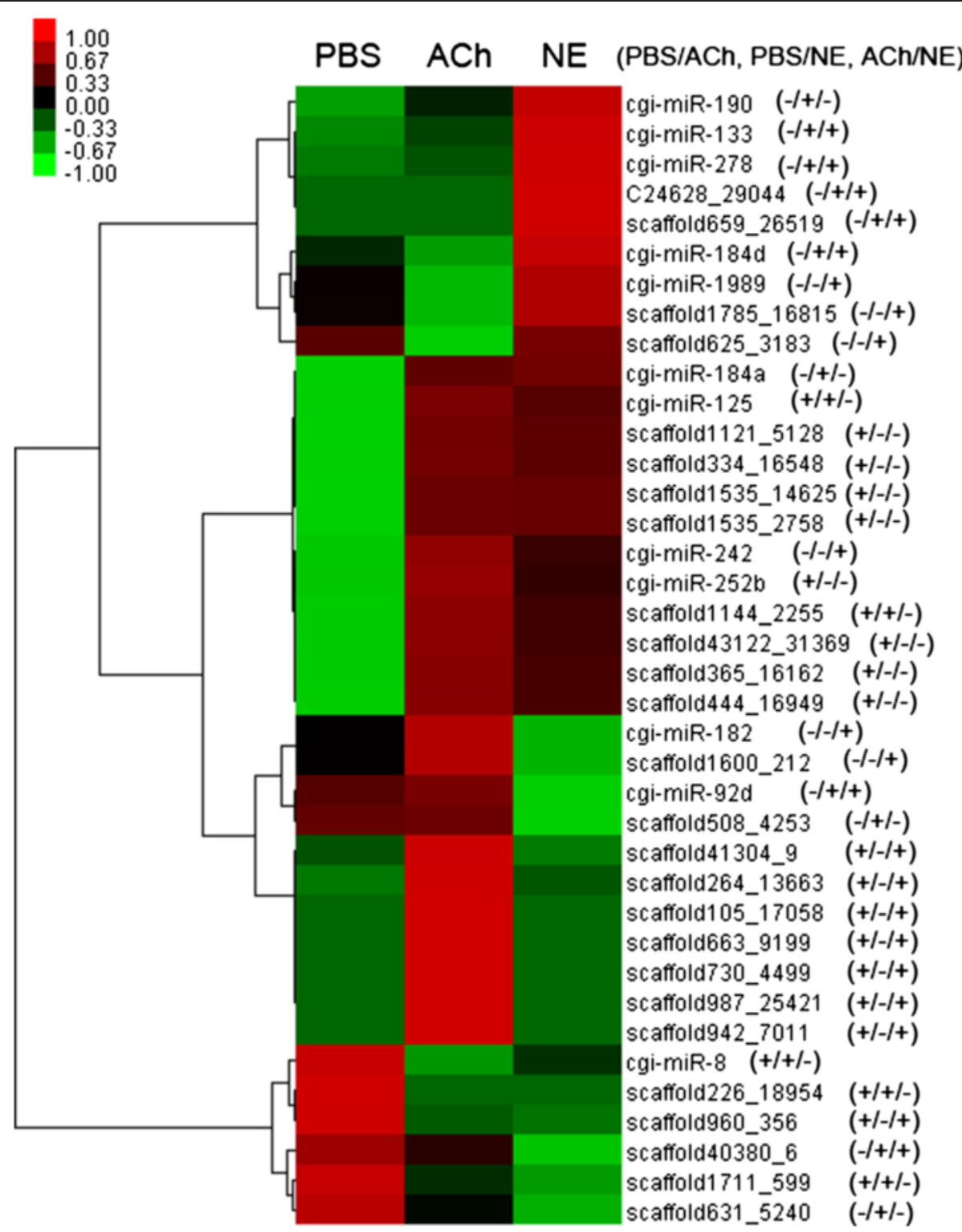

Fig. 4 Heat map and hierarchical clustering of differentially expressed miRNAs. Neurotransmitter-responsive miRNAs were clustered with converted FPKM value by Cluster 3.0 in default settings. Converted expressions of certain miRNA were shown with different colors. The "+" or "-" symbol after each miRNA ID indicates its significance state of expression difference in PBS/ACh, PBS/NE, ACh/NE comparison with " + " represents significant difference and "-" represents no significant difference

responsive [18]. Furthermore, some immune-related biological process (death, immune system process and response to stimulus) and molecular function (antioxidant) were annotated from the target genes of those 38 neurotransmitter-responsive miRNAs (Fig. 5), which collectively implied the potential immunomodulation role of the neurotransmitter-responsive miRNAs in oyster. Moreover, those 38 neurotransmitter-responsive miRNAs were clustered into eight distinct branches based on their FPKM value (Fig. 4), where miRNAs in the same branch shared similar expression pattern after the neurotransmitter stimulation. Those miRNAs with similar expression pattern were suspected to function synergistically to maintain the homeostasis of NEI system in oyster. Interestingly, most of the neurotransmitterresponsive miRNAs were newly discovered ones in this species, indicating the existence of novel miRNA regulation mechanism in the NEI system of oyster.

NeurimmiRs represent a class of miRNAs which could modulate the interactions in NEI system [10]. In the present study, multiple genes involved in the pathogen recognition, signaling transduction and immune function were predicted as targets of NeurimmiRs in oyster. PRRs are the first players to initiate the immune response by 


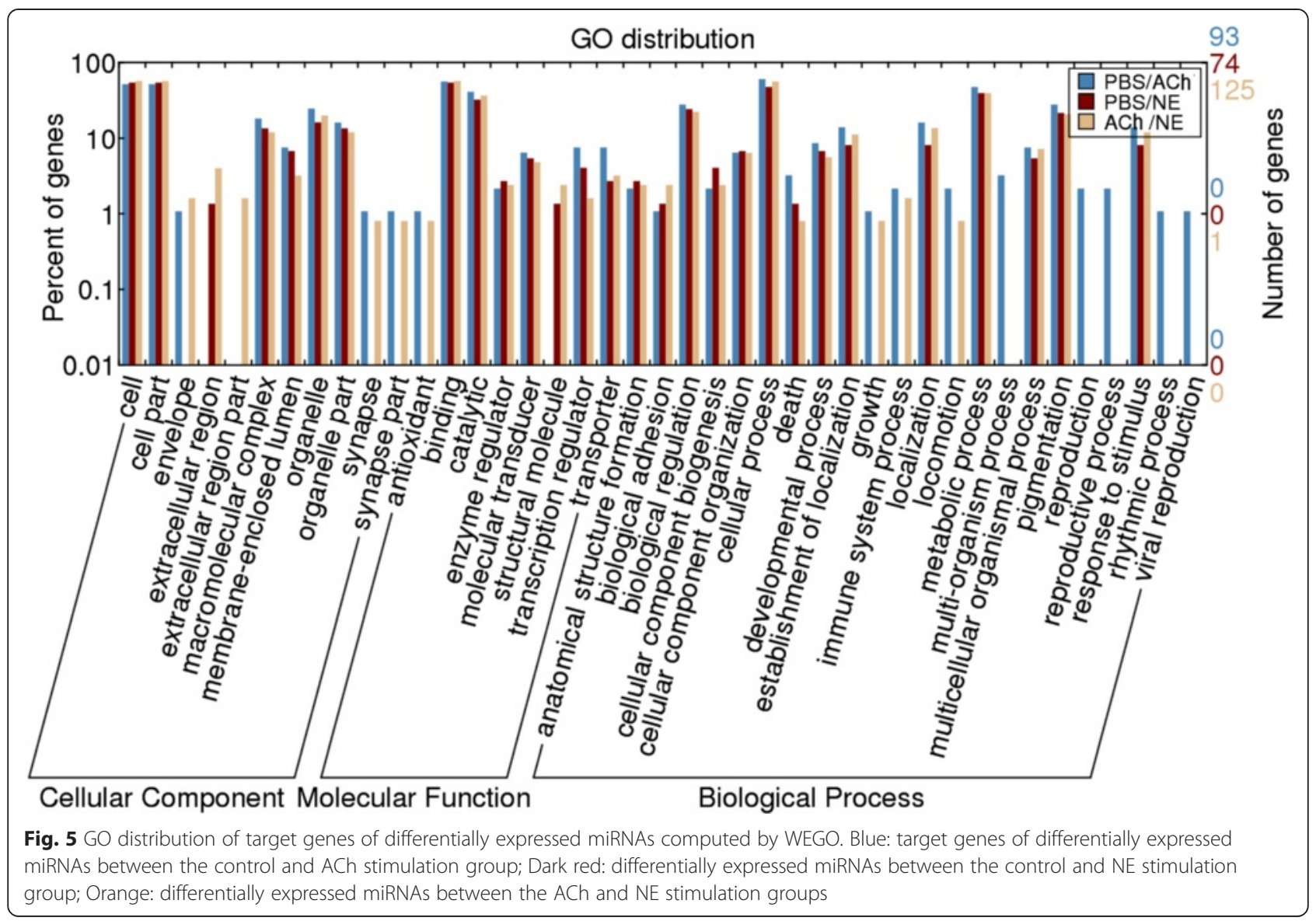

recognizing pathogens [25]. As invertebrates, oysters have evolved a sophisticated innate immune system with large number of PRRs to survive from harsh environment full of pathogens $[16,17,26]$. It is found in the present study that NeurimmiRs from oyster could modulate some PRRs, such as mannose receptors [27], TLRs [28] and CEACAM5 [29]. Moreover, some intracellular receptors triggering immune response could also be targeted by oyster NeurimmiRs. For example, MEGF10, a bona fide homology of engulfment receptor cell death abnormality protein-1 which could promote cellular engulfment by cooperation with ATP binding cassette transporter [30], was annotated as a putative target of scaffold987_25421. Besides, CD63, which could act as the membrane receptor of metalloproteinase inhibitor (TIMP) and specially inhibit metalloproteinase from pathogenic bacteria Vibrio splendidus of oyster [31], was also found to be modulated by NeurimmiR scaffold444_16949. Collectively, those results suggest a dynamic regulation of NeurimmiRs in recognizing pathogens and triggering downstream immune signals in oyster.

Meanwhile, multiple signaling transducers and immune effectors were also proposed to be modulated by oyster NeurimmiRs. In the present study, two Rab genes (RAB-21 and RAB-5C), activators in integrin pathway
[32], were found to be modulated by NeurimmiR scaffold625_3183 and scaffold987_25421, respectively. Three vital regulators in NF- $\mathrm{kB}$ pathway [33, 34] (CREBBP [35], MIB2 [36] and TRAF3 [37]) were also predicated as targets of ACh-responsive NurimmiRs (scaffold987_25421, scaffold987_25421 and scaffold365_16162). However, the expression pattern of scaffold625_3183 and scaffold987_25421 was opposite, while CREBBP, MIB2 and TRAF3 conflicts with each other in activating NF- $\mathrm{kB}$. It was speculated that contradictions in modulating integrin pathway and NF-kB pathway by those NeurimmiRs could render a flexible switch on the immune response of oysters. Moreover, some NurimmiRs could also target the immune effectors in oyster. For example, IFI44, a virus-responsive gene activated by TLR3 to inhibit virus proliferation $[38,39]$, was annotated as putative target of scaffold1121_5128. Similarly, multiple NE-responsive NeurimmiRs were suggested to manipulate the expression of HSP70 [40], an important regulator in immune response.

Given the pathways and genes, the immunomodulation mechanism of $\mathrm{ACh}$ and NE might share certain similarities or was sometimes in an neurotransmitterspecific manner [41-44]. This can also be observed in those ACh- and NE-responsive miRNAs from oyster. 
Table 1 Immune-related genes putatively targeted by NeurimmiRs

\begin{tabular}{|c|c|c|c|c|c|}
\hline Classification & Target Gene & Gene ID & $\begin{array}{l}\text { NCBI Accession } \\
\text { Number }\end{array}$ & miRNA & $\begin{array}{l}\text { miRNA } \\
\text { Expression }\end{array}$ \\
\hline \multirow[t]{8}{*}{ Receptors } & $\begin{array}{l}\text { carcinoembryonic antigen-related cell adhesion } \\
\text { molecule } 5 \text { (CEACAM5) }\end{array}$ & CGI_10010080 & EKC30453 & cgi-miR-242 & $\operatorname{ACh}\left(+^{1}\right)$ \\
\hline & C-type mannose receptor 2 (MRC2) & CGI_10013598 & EKC36613 & scaffold987_25421 & $\mathrm{ACh}(+)$ \\
\hline & Toll like receptor 1 (TLR1) & CGI_10021136 & EKC32484 & scaffold43122_31369 & $\mathrm{ACh}(+)$ \\
\hline & $\begin{array}{l}\text { multiple epidermal growth factor-like domains } 10 \\
\text { (MEGF10) }\end{array}$ & CGI_10022484 & EKC30915 & scaffold987_25421 & $\mathrm{ACh}(+)$ \\
\hline & CD63 antigen (CD63) & CGI_10024556 & EKC30322 & scaffold444_16949 & $\mathrm{ACh}(+)$ \\
\hline & muscarinic acetylcholine receptor (mAChR) & CGI_10026715 & EKC38948 & scaffold1535_2758 & $\mathrm{ACh}(+)$ \\
\hline & macrophage mannose receptor 1 (MRC1) & CGI_10003643 & EKC21607 & scaffold659_26519 & NE $(+)$ \\
\hline & nicotinic acetylcholine receptor (nAChR) & CGI_10012300 & EKC27791 & cgi-miR-1989 & NE $(+)$ \\
\hline \multirow{7}{*}{$\begin{array}{l}\text { Signaling } \\
\text { molecules }\end{array}$} & CREB-binding protein (CREBBP) & CGI_10004570 & EKC21118 & scaffold987_25421 & $\mathrm{ACh}(+)$ \\
\hline & Ras-related protein Rab-21 (RAB-21) & CGI_10012407 & EKC30126 & scaffold625_3183 & $\operatorname{ACh}\left(-^{2}\right)$ \\
\hline & E3 ubiquitin-protein ligase mib2 (MIB2) & CGl_10012437 & EKC24345 & scaffold987_25421 & $\mathrm{ACh}(+)$ \\
\hline & Ras-related protein Rab-5C (RAB-5C) & CGI_10016941 & EKC27651 & scaffold987_25421 & $\mathrm{ACh}(+)$ \\
\hline & TNF receptor-associated factor 3 (TRAF3) & CGI_10019401 & EKC37852 & scaffold365_16162 & $\mathrm{ACh}(+)$ \\
\hline & TNF alpha-induced protein 3 (TNFAIP3) & CGI_10016154 & EKC18030 & cgi-miR-1989 & NE $(+)$ \\
\hline & suppressor of G2 allele of SKP1 homolog (SUGT1) & CGI_10016471 & EKC33616 & cgi-miR-184d & NE $(+)$ \\
\hline \multirow[t]{9}{*}{ Immune effector } & Catalase (CAT) & CGI_10003354 & EKC25821 & scaffold987_25421 & $\mathrm{ACh}(+)$ \\
\hline & heat shock 70 kda (HSP70) & CGI_10006158 & - & scaffold625_3183 & $\mathrm{ACh}(-)$ \\
\hline & interferon-induced protein 44 (IFI44) & CGl_10011953 & EKC23550 & scaffold1121_5128 & $\mathrm{ACh}(+)$ \\
\hline & HSP70 & CGI_10014234 & - & scaffold444_16949 & $\mathrm{ACh}(+)$ \\
\hline & HSP70 & CGl_10014235 & XP_011426978 & scaffold444_16949 & $\mathrm{ACh}(+)$ \\
\hline & complement C1q-like protein 4 (C1qL4) & CGI_10026904 & EKC37620 & scaffold105_17058 & $\mathrm{ACh}(+)$ \\
\hline & cytochrome p450 (P450) & CGl_10011491 & EKC33448 & scaffold659_26519 & NE $(+)$ \\
\hline & P450 & CGl_10012275 & EKC18482 & cgi-miR-184a & $\mathrm{NE}(+)$ \\
\hline & HSP70 & CGI_10027276 & EKC43179 & cgi-miR-184a & $\mathrm{NE}(+)$ \\
\hline
\end{tabular}

${ }^{1}$ miRNA increased in corresponding group

${ }^{2}$ miRNA decreased in corresponding group

For example, five out of 38 neurotransmitter-responsive miRNAs (cgi-miR-125, cgi-miR-8, scaffold1144_2255, scaffold1711_599 and scaffold226_18954) showed similar expression pattern after ACh or NE stimulation, and immune-related GO terms including response to stimulus and gene expression were annotated from their target genes (Fig. 10a). Those miRNAs confirmed the perspective that ACh and NE could partly share conserved immunomodulation pathway. On the other hand, 21 miRNAs exhibited different expression pattern after ACh or NE stimulation, with six of them (cgi-miR-182, cgi-miR-242, scaffold1600_212, cgi-miR-1989, scaffold1785_16815 and scaffold625_3183) in an opposite trend. Among them, cgi-miR-1989 was of the most interest as it decreased in ACh group while increased in NE group and was a putative regulator of TNFAIP3 and nAChR (Fig. 11). It was proved that TNFAIP3, a key factor in NF- $\mathrm{kB}$ pathway, could attenuate NF- $\mathrm{kB}$ activation during the infection [45] while nAChR, one of important ACh receptor, could also modulate the inflammatory responses through both NF- $\mathrm{KB}$ and JAK/ STAT pathway [46, 47]. Those differentially expressed NeurimmiRs were supposed to result in the differences between immunomodulation of ACh and NE. Moreover, the modulation differences could also be augmented by scaffold1535_2758, a putative regulator of mAChR, which was significantly up-regulated after ACh stimulation and ascended modestly after NE stimulation. It was proposed that scaffold1535_2758 could promote the nAChR-initialed signaling after ACh stimulation while suppress the cholinergic signaling remarkably after $\mathrm{NE}$ stimulation by cooperating with cgi-miR-1989. Collectively, those NeurimmiRs synergistically render the host with a closely interacted NEI system in oyster. 


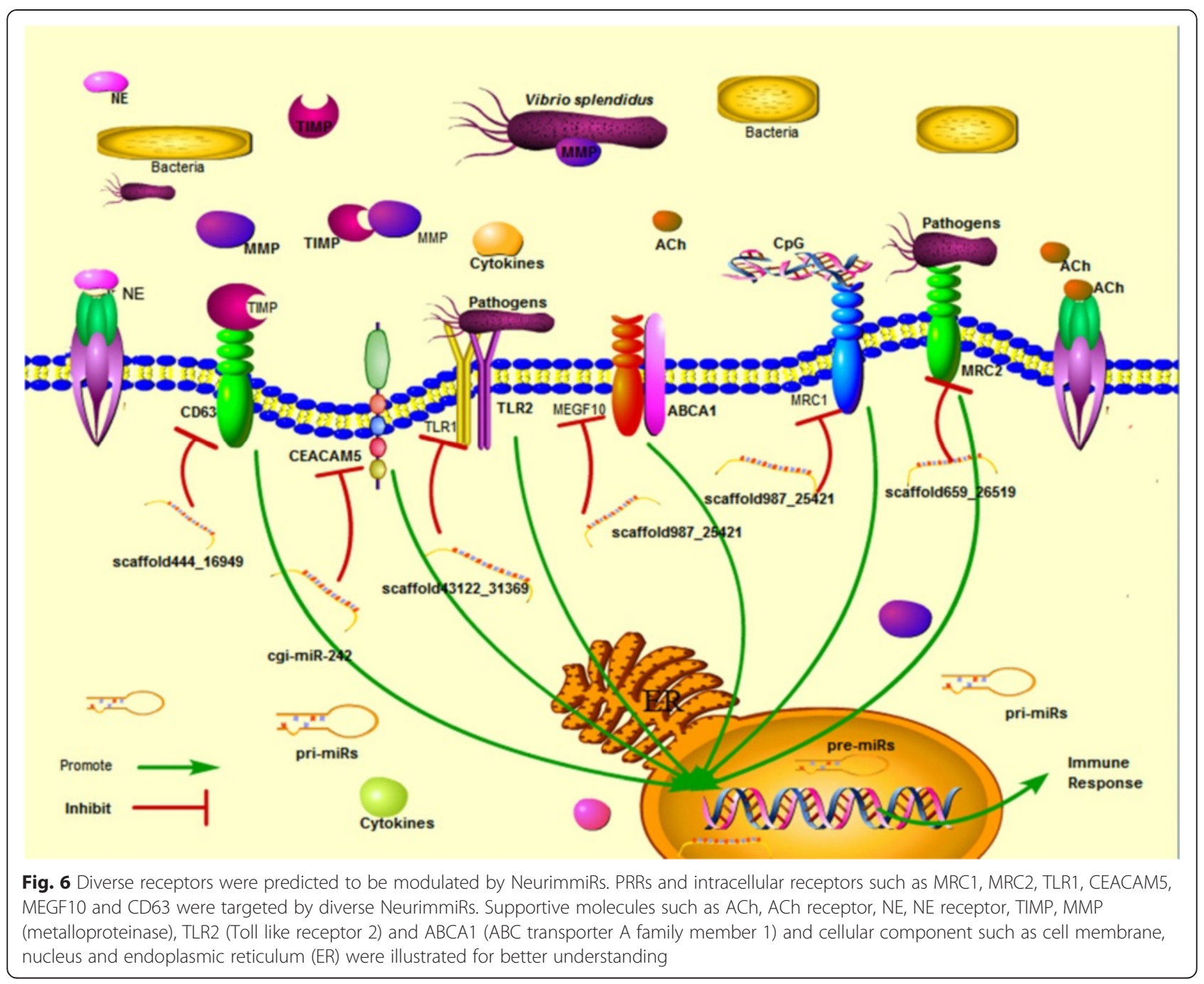

Phagocytosis of immunocytes is a highly integrated immune process, accomplished by multiple genes involved in pathogen recognition, signal transducing and immune effector expression [25, 48, 49]. In the present study, the phagocytic rate of oyster haemocytes against $V$. splendidus decreased markedly after $\mathrm{ACh}$ and $\mathrm{NE}$ stimulation (Fig. 9a), which was consistent with speculations proposed above. Comparatively, the apoptosis rate remained comparable in ACh and NE group (Fig. 9b), possibly owing to the modulatory conflicts in integrin pathway and NF- $\mathrm{KB}$ pathway, which were considered as two major players in maintaining cell survival $[50,51]$. Notwithstanding, late-apoptosis and necrosis rate decreased significantly after the neurotransmitter stimulation (Fig. 9c), indicating a tendency for ACh and NE in maintaining cell survival in oysters.

\section{Conclusion}

In conclusion, a total of 38 neurotransmitter-responsive miRNAs were identified in oyster with possible immunomodulation roles. A comprehensive NeurimmiRmediated network targeting PRRs, intracellular receptors, signaling transducers and immune effectors was proposed for oyster haemocytes to maintain the homeostasis of NEI system. Those findings for the first time depicted the interaction between invertebrate NeurimmiRs and the ancient NEI system, which would shed light on the understanding of the stress adaptation mechanisms of oyster.

\section{Materials and methods}

\section{Oyster culture}

Oysters C. gigas (averaging $150 \mathrm{~mm}$ in shell length, $70 \mathrm{~mm}$ in width) were collected from a local farm in Qingdao, China. A narrowed notch was sawed for injection in the closed side of oyster shell, which was adjacent to the adductor muscle [52]. Oysters were maintained in aerated sea water (about $20{ }^{\circ} \mathrm{C}$ ) for two weeks before use. No specific permits are required for the present study and all experiments were conducted with approval 


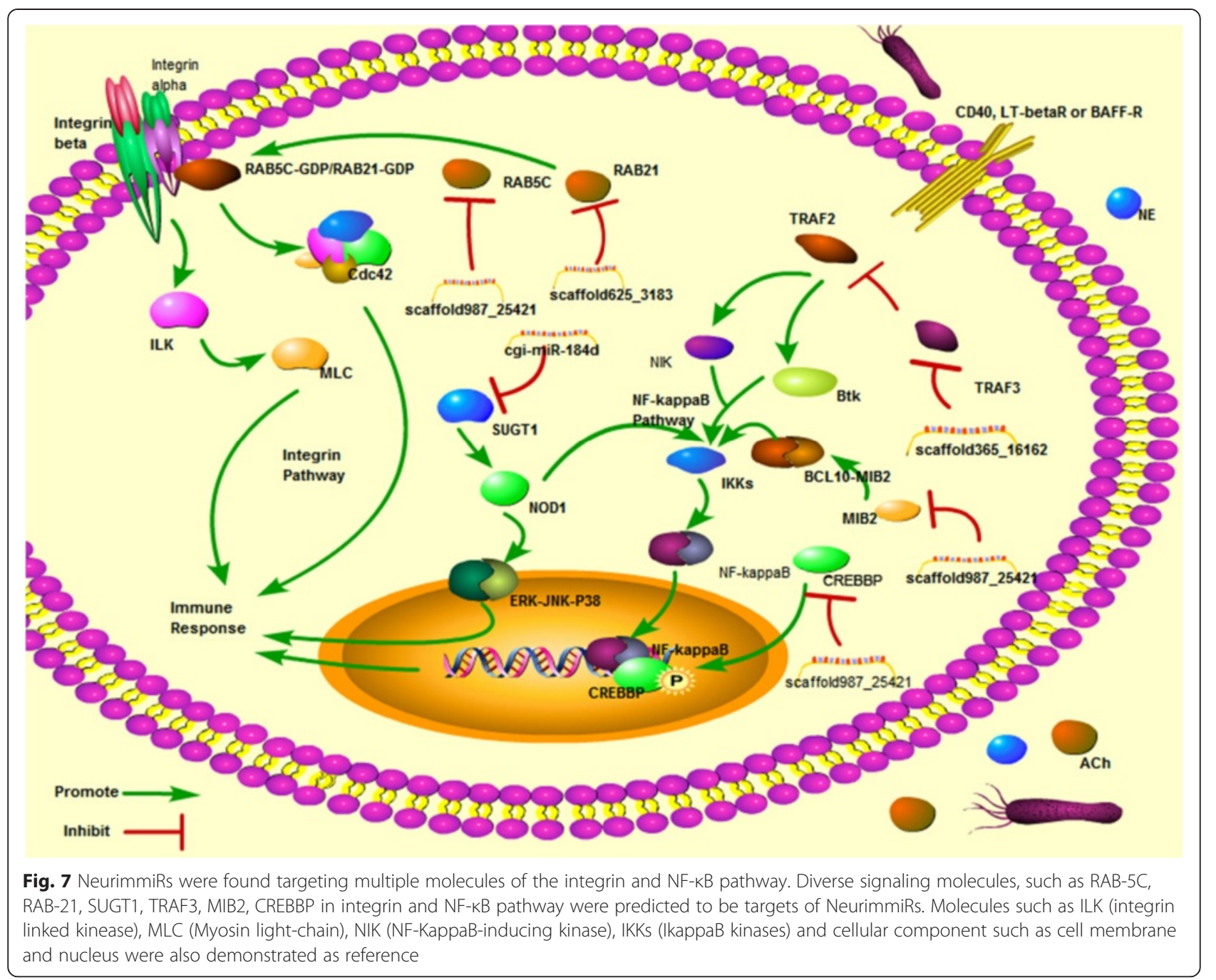

from Experimental Animal Ethics Committee, Institute of Oceanology, Chinese Academy of Sciences, China.

\section{Neurotransmitter stimulation}

A total of 30 oysters were employed for neurotransmitter stimulation experiment and randomly divided into three groups, including PBS control group, ACh stimulation group and NE stimulation group. Oysters in PBS control group received an injection of $50 \mu \mathrm{L}$ phosphate buffered saline (PBS, $0.14 \mathrm{~mol} \mathrm{~L}^{-1}$ sodium chloride, $3 \mathrm{mmol} \mathrm{L}^{-1}$ potassium chloride, $8 \mathrm{mmol} \mathrm{L}^{-1}$ disodium hydrogen phosphate dodecahydrate, $1.5 \mathrm{mmol} \mathrm{L}^{-1}$ potassium phosphate monobasic, $\mathrm{pH}$ 7.4) at their adductor muscle while oysters in $\mathrm{ACh}$ and NE group were injected with $50 \mu \mathrm{L}$ ACh (Sigma, $10^{-7} \mathrm{M}$ in PBS) and NE (Sigma, $10^{-7} \mathrm{M}$ in PBS), respectively. All oysters were returned to the aerated sea water immediately after the injection and sampled at 6 hour post injection. To reduce individual variations and improve result reliability, haemocytes from five individuals were harvested by centrifugation $\left(800 \mathrm{~g}, 4{ }^{\circ} \mathrm{C}\right.$ for
10 minutes) and pooled into one sample. Two replicates were conducted for subsequent sequencing in each group.

Another 45 oysters were also employed and received the same treatment as described above for phagocytosis and apoptosis assay. At $6 \mathrm{~h}$ post the injection, haemocytes from five oysters in each group were collected aseptically from the posterior adductor muscle sinus with acid citrate-dextrose anticoagulant agent $\left(22 \mathrm{~g} \mathrm{~L}^{-1}\right.$ sodium citrate, $8 \mathrm{~g} \mathrm{~L}^{-1}$ citric acid, $24.5 \mathrm{~g} \mathrm{~L}^{-1}$ glucose, $\mathrm{pH}$ 7.4) at the ratio of 8:1 [53] and resuspended in L15 medium (Gibco) with additional saline solution to $2 \mathrm{x}$ $10^{6}$ cells $\mathrm{mL}^{-1}$ before subjected to phagocytosis and apoptosis assay. All trials were conducted with three replicates.

\section{Construction and deep sequencing of oyster small RNA libraries}

Total miRNAs in the haemocytes were extracted with PureLink miRNA Isolation Kit (Invitrogen) according to the manufacture's protocol. RNAs were quantified by 


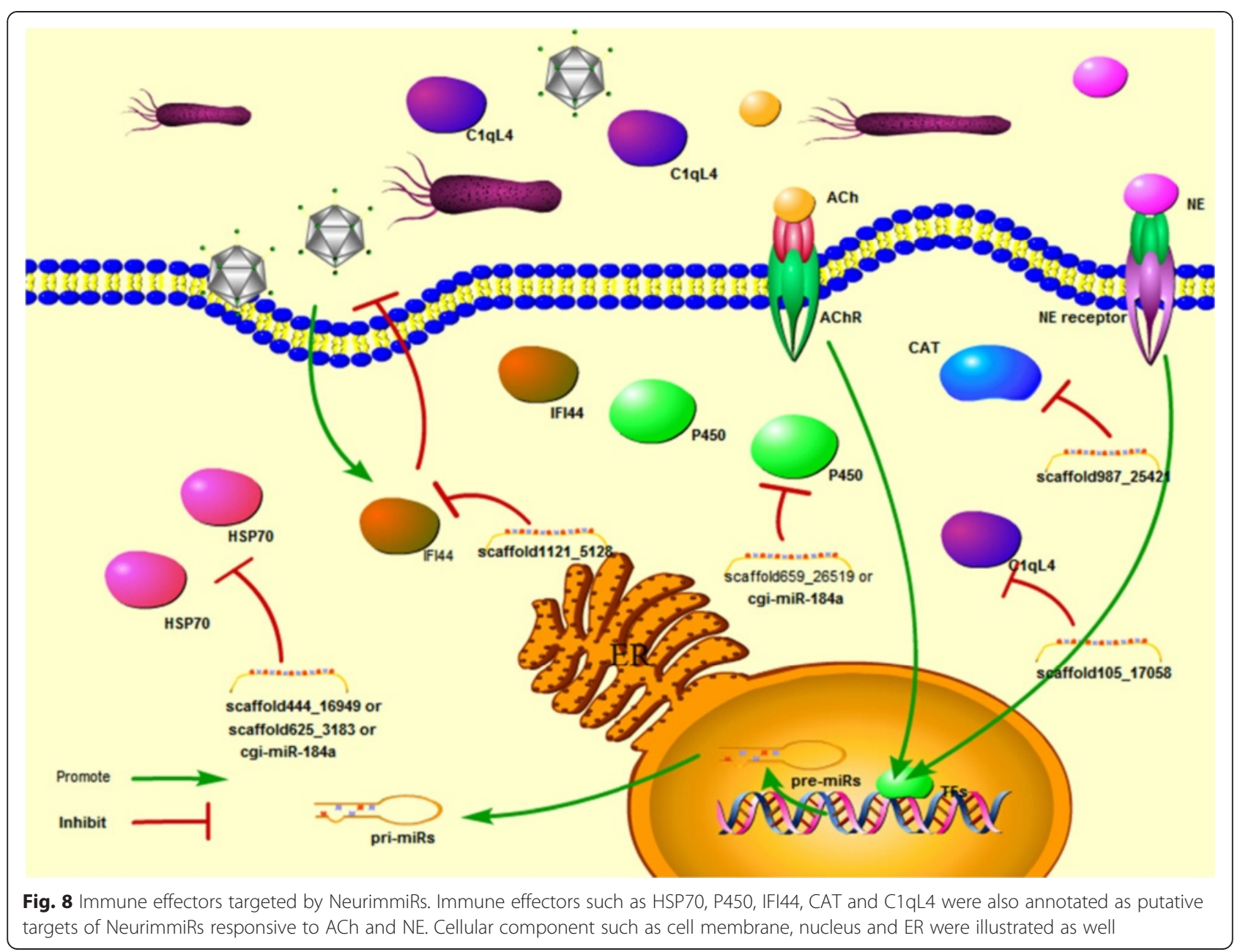

Nanodrop 2000 (Thermo Scientific), and further analyzed by Agilent 2100 Bioanalyzer (Agilent Technologies) for integrity. miRNA samples (about $3 \mu \mathrm{g}$ ) with A260/280 ratio above 2.0 were used for subsequent library construction. The construction of small RNA libraries and the following deep sequencing by Ion Torrent Proton was conducted according to manufacturer's instruction with the brief steps including (1) hybridization and ligation of the total miRNA purified by PureLink miRNA Isolation Kit, (2) reverse transcription to synthesis the cDNA, (3) purification and size-selection of the cDNA, (4) amplification and size-selection of the cDNA, (5) assess the yield and size
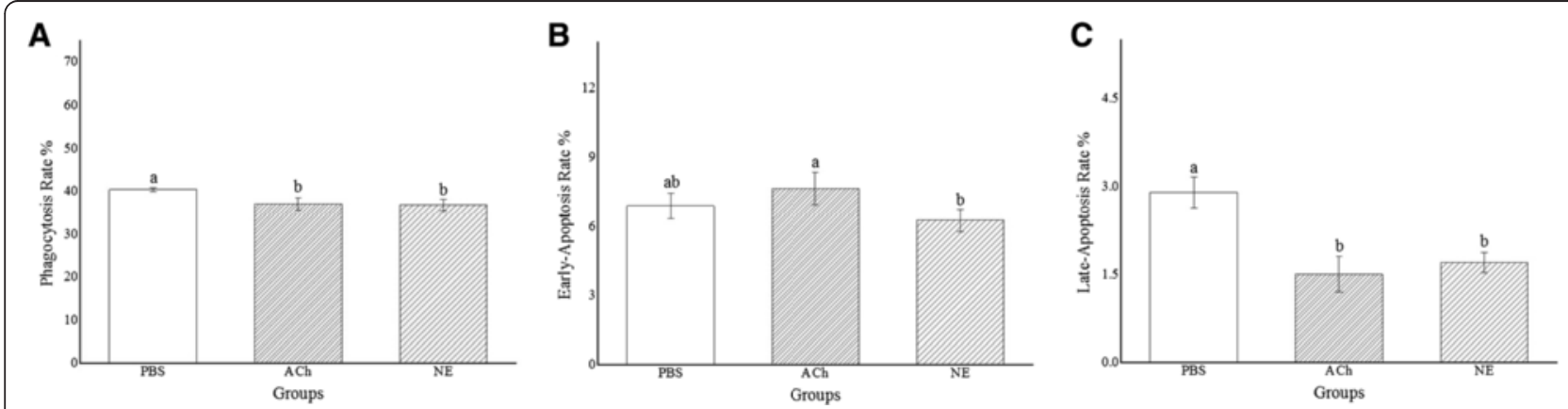

Fig. 9 Changes of haemocyte phagocytosis and apoptosis rate by ACh and NE. a Phagocytosis rate, $\mathbf{b}$ early-apoptosis rate and $\mathbf{c}$ late-apoptosis and necrosis rate of haemocytes from oysters stimulated with ACh and NE were determined using flow cytometry 


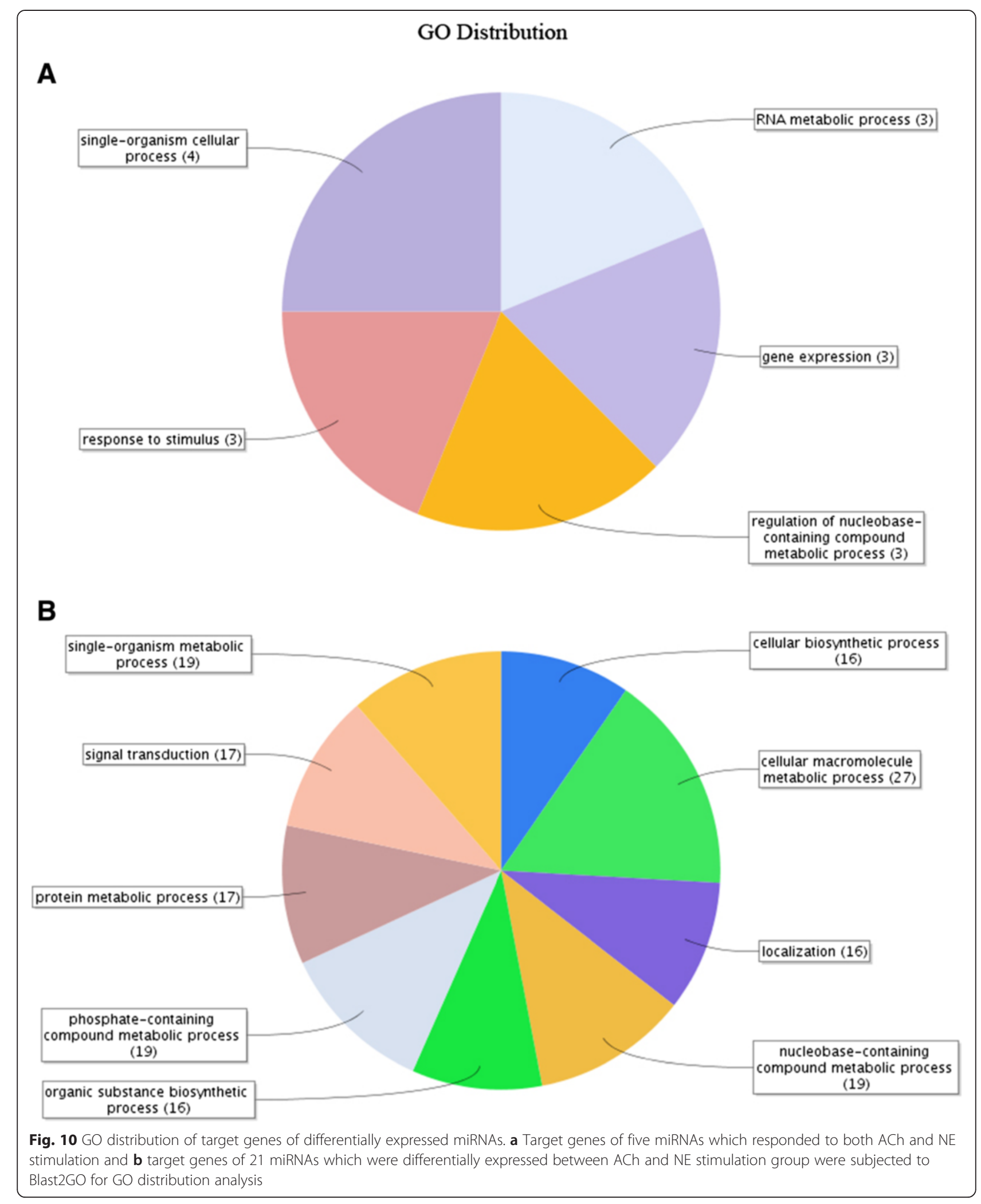




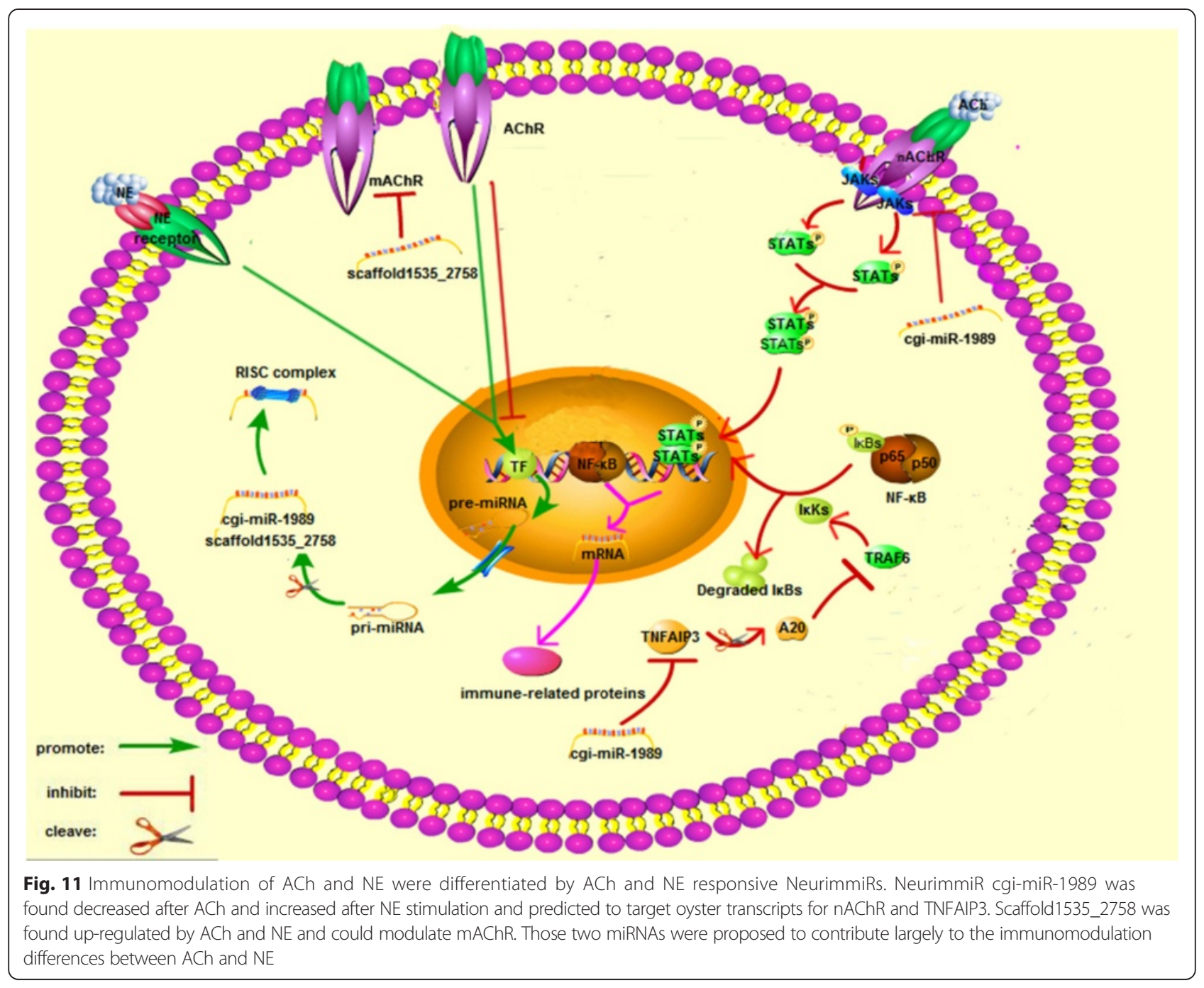

distribution of the amplified DNA using Agilent 2100 Bioanalyzer, and (6) sequencing the libraries using Ion Torrent Proton P1 chip.

\section{Identification of oyster miRNAs}

Raw data obtained from Ion Torrent Proton was preprocessed by Fastx-toolkit pipeline to get the summary of sequencing quality, nucleotide distributions and length distributions. Then reads with high sequencing quality and ranging from 18-30 nt in length were collected by Fastx-toolkit and aligned to Rfam database [54] and oyster mRNAs. After abandoning reads mapped to either non-miRNAs in Rfam (such as rRNA, snoRNA etc.) or oyster mRNAs, the remaining was then mapped to oyster genome using bowtie-1.00 software [55] and analyzed by miRDeep2 [56] to identify known and novel miRNAs with mature miRNAs and precursor sequences from oyster and other species listed in miRBase [57] as references.

\section{Expression analysis of miRNA}

The copy numbers of oyster miRNAs were calculated by home-made Perl script. The differentially expressed miRNAs were determined by edgeR software using generalized linear models with FDR (false discovering rate) value less than 0.05 [58].The expression levels of miRNAs in each group were estimated by FPKM method. A dendrogram of differentially expressed miRNAs was clustered by Cluster3.0 using FPKM value and displayed by Treeview software.

\section{Target prediction and $\mathrm{GO}$ analysis}

The 3'-UTR sequences of oyster genes were obtained based on the genome annotation information and subjected to miRanda [59] for target prediction of those neurotransmitter-responsive miRNAs. Genes were regarded as putative targets if they satisfied the criteria with free energy less than $-25 \mathrm{kcal} / \mathrm{mol}$ and score value higher than 160. 
All oyster protein sequences were aligned to nonredundant database of NCBI by a local blastp algorithm (E-value $<1 \times 10^{-5}$ ) and further parsed by Blast2GO software [60] for assigning GO terms. GO term distribution of target genes was then calculated and exhibited by WEGO [61].

\section{Phagocytosis and apoptosis assay after neurotransmitter stimulation}

Phagocytosis rate of oyster haemocytes was determined using method modified from previous report [52]. In brief, Vibrio splendidus [62], isolated from lesions of moribund scallop Patinopecten yessoensis and cultured at $16^{\circ} \mathrm{C}$ overnight, were labeled with FITC (Sigma) and diluted into $10^{8}$ cells $\mathrm{mL}^{-1}$ before use. A volume of $200 \mu \mathrm{L}$ haemocytes $\left(2 \times 10^{6}\right.$ cells $\left.\mathrm{mL}^{-1}\right)$ obtained previously was then incubated with same volume of FITC-labeled bacteria for $60 \mathrm{~min}$ at room temperature in darkness. Haemocytes were subsequently recollected and resuspended in L15 medium to detect the phagocytosis rate using flow cytometry (BD biosciences) with 10, 000 events counted.

Apoptosis rate was detected using the Annexin VFITC detection kit (Beyotime) according to the manufacturer's instructions. In brief, $195 \mu \mathrm{L}$ diluted haemocytes were incubated firstly with $5 \mu \mathrm{L}$ Annexin V-FITC for $10 \mathrm{~min}$ to label early-apoptotic cells and then stained with $10 \mu \mathrm{L}$ propidium iodide for 5 min to mark the late-apoptotic or necrotic cells. After recollection and resuspension, the haemocytes were immediately subjected to flow cytometry for apoptosis rate detection $(10,000$ events countered).

Data obtained were analyzed by Statistical Package for Social Sciences (SPSS) 19.0, followed by one-way analysis of variance (ANOVA) and given as means \pm S.D. Differences were considered significant at $P<0.05$ and marked with different letters ( $a, b, c$ etc.).

\section{Availability of supporting data}

The raw sequencing data have been deposited in the Sequence Read Archive (SRA) under BioProject SRR1562260.

\section{Additional files}

Additional file 1: Table S1. Statistics for the distribution of reads filtered in order. (DOCX $15 \mathrm{~kb}$ )

Additional file 2: Figure S1. Sequence length distribution of the libraries. $X$ axis displays the reads length; $Y$ axis shows the amount (by million reads). (PDF 177 kb)

Additional file 3: Table S2. Statistics for the filtered clean reads. (DOCX $13 \mathrm{~kb}$ )

Additional file 4: Table S3. miRNAs identified in the present study and previous study. (XLSX $20 \mathrm{~kb}$ )

Additional file 5: Table S4. miRNAs with dual precursors in genome identified in the present study. (XLSX $15 \mathrm{~kb}$ )
Additional file 6: Table S5. FPKM values of 331 miRNAs identified in C.gigas. (XLSX $34 \mathrm{~kb}$ )

Additional file 7: Table S6. Differentially expressed miRNAs identified by edgeR software at FDR $<0.05$. (XLSX $9 \mathrm{~kb}$ )

Additional file 8: Table S7. Neurotransmitter-responsive miRNAs and their target genes predicted by miRanda. (XLSX 17 kb)

\section{Competing interests}

The authors declare that they have no competing interests.

\section{Authors' contributions}

HC, ZQL and WLW purified RNA, ZHH, DHG and QG carried out deep sequencing. $\mathrm{HC}$ and $\mathrm{ZZ}$ carried out bioinformatics analyses. HC, LLW wrote the manuscript. HC, ZZ, LLW, MQW and SLS participated in the design of the study and discussed the results. LLW and LSS conceived the study. All authors have read and approved the final manuscript.

\section{Acknowledgments}

The authors thank all members of the laboratory for valuable discussions. This research was supported by the earmarked fund for Modern Agroindustry Technology Research System (CARS- 48), grants from NSFC (No. 41276169 to LLW; No. 41206151 to ZZ, http://www.nsfc.gov.cn/) and the fund from Taishan Scholar Program of Shandong, China.

\section{Author details}

${ }^{1}$ Key Laboratory of Experimental Marine Biology, Institute of Oceanology, Chinese Academy of Sciences, Qingdao, China. ${ }^{2}$ Key Laboratory of Mariculture \& Stock enhancement in North China's Sea, Ministry of Agriculture, Dalian Ocean University, Dalian 116023, China. ${ }^{3}$ University of Chinese Academy of Sciences, Beijing, China.

Received: 11 September 2014 Accepted: 26 October 2015

Published online: 14 November 2015

\section{Reference}

1. Besedovsky H, Sorkin E. Network of immune-neuroendocrine interactions. Clin Exp Immunol. 1977;27(1):1-12.

2. Webster JI, Tonelli L, Sternberg EM. Neuroendocrine regulation of immunity. Annu Rev Immunol. 2002;20:125-63.

3. Kohm AP, Sanders VM. Norepinephrine: a messenger from the brain to the immune system. Trends Immunol. 2000;21(11):539-42.

4. Resende RR, Adhikari A. Cholinergic receptor pathways involved in apoptosis, cell poliferation and neurol differentiation. Cell Commun Signal. 2009;7:20.

5. van der Zanden EP, Snoek SA, Heinsbroek SE, Stanisor OI, Verseijden C, Boeckxstaens GE, et al. Vagus nerve activity augments intestinal macrophage phagocytosis via nicotinic acetylcholine receptor a4ß2. Gastroenterology. 2009;137(3):1029-39.

6. Sternberg EM. Neural regulation of innate immunity: a coordinated nonspecific host response to pathogens. Nat Rev Immunol. 2006;6(4):318-28.

7. Ambros V. The functions of animal microRNAs. Nature. 2004;431:350-5.

8. Bartel DP. MicroRNAs: target recognition and regulatory functions. Cell. 2009;136(2):215-33.

9. Ambros V. MicroRNA pathways in flies and worms: growth, death, fat, stress, and timing. Cell. 2003;113(6):673-6.

10. Soreq $H$, Wolf $Y$. NeurimmiRs: microRNAs in the neuroimmune interface. Trends Mol Med. 2011;17(10):548-55.

11. Shaked I, Meerson A, Wolf Y, Avni R, Greenberg D, Gilboa-Geffen A, et al. MicroRNA-132 potentiates cholinergic anti-inflammatory signaling by targeting acetylcholinesterase. Immunity. 2009;31(6):965-73.

12. Shaltiel G, Hanan M, Wolf $Y$, Barbash S, Kovalev E, Shoham S, et al. Hippocampal microRNA-132 mediates stress-inducible cognitive deficits through its acetylcholinesterase target. Brain Struct Funct. 2013;218(1):59-72.

13. Shi XW, Zhou Z, Wang LL, Yue F, Wang MQ, Yang CY, et al. The immunomodulation of acetylcholinesterase in Zhikong scallop Chlamys farreri. PLoS One. 2012;7(1):e30828.

14. Zhou Z, Wang LL, Shi XW, Zhang H, Gao Y, Wang MQ, et al. The modulation of catecholamines to the immune response against bacteria Vibrio anguillarum challenge in scallop Chlamys farreri. Fish Shellfish Immun. 2011;31(6):1065-71. 
15. Wang LL, Qiu LM, Zhou Z, Song LS. Research progress on the mollusc immunity in China. Dev Comp Immunol. 2013;39(1-2):2-10.

16. Zhang GF, Fang XD, Guo XM, Li L, Luo RB, Xu F, et al. The oyster genome reveals stress adaptation and complexity of shell formation. Nature. 2012;490(7418):49-54.

17. Zhang LL, Li L, Guo XM, Litman GW, Dishaw LJ, Zhang GF. Massive expansion and functional divergence of innate immune genes in a protostome. Sci Rep-UK. 2015;5:8693.

18. Zhou Z, Wang LL, Song LS, Liu R, Zhang H, Huang MM, et al. The identification and characteristics of immune-related microRNAs in haemocytes of oyster Crassostrea gigas. PLoS One. 2014;9(2):e88397.

19. Ottaviani E. The mollusc as a suitable model for mammalian immuneneuroendocrine investigations. ISJ-Invert Surviv J. 2004;1:2-4.

20. Kim VN. MicroRNA biogenesis: coordinated cropping and dicing. Nat Rev Mol Cell Bio. 2005;6(5):376-85.

21. Wheeler BM, Heimberg AM, Moy VN, Sperling EA, Holstein TW, Heber S, et al. The deep evolution of metazoan microRNAs. Evol Dev. 2009;11(1):50-68.

22. Jiao $Y$, Zheng Z, Du XD, Wang $Q H$, Huang RL, Deng $Y W$, et al. Identification and characterization of microRNAs in pearl oyster Pinctada martensii by Solexa deep sequencing. Mar Biotechnol. 2014;16(1):54-62.

23. Reardon C, Gordon SD, Brustle A, Brenner D, Tusche MW, Olofsson PS, et al. Lymphocyte-derived $A C h$ regulates local innate but not adaptive immunity. Proc Natl Acad Sci U S A. 2012;110(4):1410-5.

24. Pavlov VA, Tracey KJ. Neural regulators of innate immune responses and inflammation. Cell Mol Life Sci. 2004;61(18):2322-31.

25. Akira $S$, Uematsu $S$, Takeuchi O. Pathogen recognition and innate immunity. Cell. 2006;124(4):783-801.

26. Meng J, Zhang LL, Huang BY, Li L, Zhang GF. Comparative analysis of oyster (Crassostrea gigas) immune responses under challenge by different Vibrio strains and conditions. Molluscan Res. 2014;35(1):1-11.

27. Stahl PD, Ezekowitz RAB. The mannose receptor is a pattern recognition receptor involved in host defense. Curr Opin Immunol. 1998;10(1):50-5.

28. Akira S, Takeda K. Toll-like receptor signalling. Nat Rev Immunol. 2004;4(7):499-511.

29. Schmitter T, Agerer F, Peterson L, Münzner P, Hauck CR. Granulocyte CEACAM3 is a phagocytic receptor of the innate immune system that mediates recognition and elimination of human-specific pathogens. J Exp Med. 2004;199(1):35-46.

30. Hamon Y, Trompier D, Ma Z, Venegas V, Pophillat M, Mignotte V, et al. Cooperation between engulfment receptors: the case of $A B C A 1$ and MEGF10. PLoS One. 2006;1(1):e120.

31. Binesse J, Delsert C, Saulnier D, Champomier-Verges MC, Zagorec M Munier-Lehmann $\mathrm{H}$, et al. Metalloprotease vsm is the major determinant of toxicity for extracellular products of Vibrio splendidus. Appl Environ Microb(Aem). 2008;23:7108-17.

32. Reyes-Reyes M, Mora N, Gonzalez G, Rosales C. $\beta 1$ and $\beta 2$ integrins activate different signalling pathways in monocytes. Biochem J. 2002;363:273-80.

33. Ghosh S, May MJ, Kopp EB. NF-kB and Rel proteins: evolutionarily conserved mediators of immune responses. Annu Rev Immunol. 1998;16:225-60.

34. Tripathi $P$, Aggarwal A. NF-kB transcription factor: a key player in the generation of immune response. Curr Sci India. 2006;90(4):519-31.

35. Gerritsen ME, Williams AJ, Neish AS, Moore S, Shi Y, Collins T. CREB-binding protein p300 are transcriptional coactivators of p65. Proc Natl Acad Sci U S A. 1997:94:2927-32.

36. Stempin CC, Chi L, Giraldo-Vela JP, High AA, Häcker H, Redecke V. The E3 ubiquitin ligase mind bomb-2 (MIB2) protein controls B-cell CLL/lymphoma 10 (BCL10)-dependent NF-KB activation. J Biol Chem. 2011;286(43):37147-57.

37. Vallabhapurapu S, Matsuzawa A, Zhang W, Tseng P-H, Keats JJ, Wang H, et al. Nonredundant and complementary functions of TRAF2 and TRAF3 in a ubiquitination cascade that activates NIK-dependent alternative NF-KB signaling. Nat Immunol. 2008:9(12):1364-70.

38. Deshmukh US, Nandula SR, Thimmalapura P-R, Scindia YM, Bagavant $\mathrm{H}$. Activation of innate immune responses through Toll-like receptor 3 causes a rapid loss of salivary gland function. J Oral Pathol Med. 2009;38(1):42-7.

39. Power D, Santoso N, Dieringer M, Yu J, Huang H, Simpson S, et al. IFI44 suppresses HIV-1 LTR promoter activity and facilitates its latency. Virology. 2015:481:142-50.

40. Vabulas RM, Ahmad-Nejad P, Ghose S, Kirschning CJ, Issels RD, Wagner $H$. HSP70 as endogenous stimulus of the Toll/interleukin-1 receptor signal pathway. J Biol Chem. 2002;277(17):15107-12.
41. Maayan ML, Volpert EM, From A. Acetylcholine and norepinephrine: compared actions on thyroid metabolism. Endocrinology. 1983;112(4):1358-62.

42. Goyarts E, Matsui M, Mammone T, Bender AM, Wagner JA, Maes D, et al. Norepinephrine modulates human dendritic cell activation by altering cytokine release. Exp Dermatol. 2008;17(3):188-96.

43. Els RK, Palkovits M. Catecholaminergic systems in stress: structural and molecular genetic approaches. Physiol Rev. 2009;89:535-606.

44. Pavlov VA, Wang H, Czura CJ, Friedman SG, Tracey KJ. The cholinergic anti-inflammatory pathway: a missing link in neuroimmunomodulation. Mol Med. 2003;9(5-8):125-34

45. Heyninck K, Beyaert R. A20 inhibits NF-KB activation by dual ubiquitin-editing functions. Trends Biochem Sci. 2005;30(1):1-4.

46. Wang H, Yu M, Ochani M, Amella CA, Tanovic M, Susarla S, et al. Nicotinic acetylcholine receptor a7 subunit is an essential regulator of inflammation. Nature. 2003;421(6921):384-8.

47. de Jonge WJ, van der Zanden EP, The FO, Bijlsma MF, van Westerloo DJ, Bennink RJ, et al. Stimulation of the vagus nerve attenuates macrophage activation by activating the Jak2-STAT3 signaling pathway. Nat Immunol. 2005;6(8):844-51.

48. Janeway Jr CA, Medzhitov R. Innate immune recognition. Annu Rev Immunol. 2002:20:197-216.

49. Underhill DM, Ozinsky A. Phagocytosis of microbes: complexity in action. Annu Rev Immunol. 2002;20:825-52.

50. Meredith Jr JE, Schwartz MA. Integrins, adhesion and apoptosis. Trends Cell Biol. 1997;7(4):146-50.

51. Siebenlist U, Franzoso G, Brown K. Structure, regulation and function of NF-kB. Annu Rev Cell Biol. 1994;10:405-55.

52. Zhang T, Qiu LM, Sun ZB, Wang LL, Zhou Z, Liu R, et al. The specifically enhanced cellular immune responses in Pacific oyster (Crassostrea gigas) against secondary challenge with Vibrio splendidus. Dev Comp Immunol. 2014:45(1):141-50.

53. Wang WL, Liu R, Zhang $T$, Zhang $R$, Song XR, Wang LL, et al. A novel phagocytic receptor ( $\mathrm{gNimC}$ ) from Pacific oyster Crassostrea gigas with lipopolysaccharide and gram-negative bacteria binding activity. Fish Shellfish Immun. 2015:43:103-10.

54. Burge SW, Daub J, Eberhardt R, Tate J, Barquist L, Nawrocki EP, et al. Rfam 11.0: 10 years of RNA families. Nucleic Acids Res. 2013:41(Database issue):D226-32.

55. Langmead B, Trapnell C, Pop M, Salzberg SL. Ultrafast and memory-efficient alignment of short DNA sequences to the human genome. Genome Biol. 2009:10(3):R25

56. Friedlander MR, Mackowiak SD, Li N, Chen W, Rajewsky N. miRDeep2 accurately identifies known and hundreds of novel microRNA genes in seven animal clades. Nucleic Acids Res. 2011:40(1):37-52.

57. Kozomara A, Griffiths-Jones S. miRBase: annotating high confidence microRNAs using deep sequencing data. Nucleic Acids Res. 2014;42(Database issue):D68-73.

58. Robinson MD, McCarthy DJ, Smyth GK. edgeR: a Bioconductor package for differential expression analysis of digital gene expression data. Bioinformatics. 2010;26(1):139-40.

59. Kurubanjerdjit N, Huang CH, Lee YL, Tsai JJP, Ng KL. Prediction of microRNA-regulated protein interaction pathways in Arabidopsis using machine learning algorithms. Comput Biol Med. 2013;43(11):1645-52.

60. Conesa A, Götz S. Blast2GO: a comprehensive suite for functional analysis in plant genomics. Int J Plant Genomics. 2008;2008:1-12.

61. Ye J, Fang $L$, Zheng $H$, Zhang $Y$, Chen J, Zhang Z, et al. WEGO: a web tool for plotting GO annotations. Nucleic Acids Res. 2006;34(Web Server issue):W293-297

62. Liu R, Qiu LM, Yu ZA, Zi J, Yue F, Wang LL, et al. Identification and characterisation of pathogenic Vibrio splendidus from Yesso scallop (Patinopecten yessoensis) cultured in a low temperature environment. J Invertebr Pathol. 2013;114(2):144-50. 